\title{
Nanoscale earthquake records preserved in plagioclase microfractures from the lower continental crust
}

\author{
Arianne J. Petley-Ragan ${ }^{1}$, Oliver Plümper ${ }^{2}$, Benoit Ildefonse ${ }^{3}$, and Bjørn Jamtveit ${ }^{1}$ \\ ${ }^{1}$ Physics of Geological Processes, the Njord centre, University of Oslo, Oslo, Norway \\ ${ }^{2}$ Department of Earth Sciences, Utrecht University, Utrecht, the Netherlands \\ ${ }^{3}$ Géosciences Montpellier, CNRS, University of Montpellier, Université des Antilles, Montpellier, France
}

Correspondence: Arianne J. Petley-Ragan (a.j.petley-ragan@geo.uio.no)

Received: 27 August 2020 - Discussion started: 28 September 2020

Revised: 4 February 2021 - Accepted: 15 March 2021 - Published: 23 April 2021

\begin{abstract}
Seismic faulting causes wall rock damage, which is driven by both mechanical and thermal stress. In the lower crust, co-seismic damage increases wall rock permeability, permits fluid infiltration and triggers metamorphic reactions that transform rock rheology. Wall rock microstructures reveal high-stress conditions near earthquake faults; however, there is limited documentation on the effects of a thermal pulse coupled with fluid infiltration. Here, we present a transmission electron microscopy study of co-seismic microfractures in plagioclase feldspar from lower crustal granulites from the Bergen Arcs, Western Norway. Focused ion beam foils are collected $1.25 \mathrm{~mm}$ and $1.8 \mathrm{~cm}$ from a $1.3 \mathrm{~mm}$ thick eclogite facies pseudotachylyte vein. Dislocation-free plagioclase and K-feldspar aggregates in the microfractures record a history of fluid introduction and recovery from a short-lived high-stress state caused by slip along the nearby fault. The feldspar aggregates retain the crystallographic orientation of their host and are elongated subparallel to the pseudotachylyte. We propose that plagioclase partially amorphized along the microfractures at peak stress conditions followed by repolymerization to form dislocation-free grain aggregates. Repolymerization and recrystallization were enhanced by the infiltration of fluids that transported $\mathrm{Ca}$ and $\mathrm{K}$ into the microfractures. Subsequent cooling led to exsolution of intermediate plagioclase compositions and the formation of the Bøggild-Huttenlocher intergrowth in the grains from the fracture closest to the pseudotachylyte. Our findings provide unequivocal evidence that the introduction of fluids in the microfractures occurred within the timescale of the thermal perturbation, prompting rapid annealing of damaged wall rock soon after earthquake rupture.
\end{abstract}

\section{Introduction}

During continent-continent collisions, plagioclase-rich granulite- and amphibolite-facies rocks are strong, dry and prone to seismic faulting. In some settings, this is observed to allow fluid infiltration and subsequent metamorphism of the dry crust (Jamtveit et al., 2016). Plagioclase responds by microfracturing and fragmentation followed by fluidand stress-induced recrystallization (Mukai et al., 2014; Petley-Ragan et al., 2018; Soda and Okudaira, 2018). Grain size reduction by fracturing and subsequent nucleation and recrystallization localizes strain in the lower crust, defining a transition from brittle to crystal-plastic deformation mechanisms with the potential to develop into shear zones (Svahnberg and Piazolo, 2010; Menegon et al., 2013; Okudaira et al., 2016; Marti et al., 2017). Thus, recrystallization and subsequent shear may overprint any microstructural record of the high-intensity stress conditions created by an earthquake. Analysis of plagioclase microstructures that have not undergone extensive recrystallization may provide valuable insight into the mechanical and thermal stress experienced by the wall rock during a seismic event.

For ambient lower crustal temperatures in the range from 600 to $700^{\circ} \mathrm{C}$, the transient temperature following an earthquake may exceed $1000^{\circ} \mathrm{C}$ within $1 \mathrm{~cm}$ of the slip surface (Bestmann et al., 2012; Clerc et al., 2018). Additionally, in a purely elastic model, Reches and Dewers (2005) showed that wall rock stresses may approach $10 \mathrm{GPa}$ within $3 \mathrm{~mm}$ of a propagating rupture for a dynamic earthquake rupture propagating at $91 \%$ of the Rayleigh wave speed. Such conditions, although short-lived, are expected to drive irreversible processes within the rock record, such as thermal shock fractur- 
ing (Papa et al., 2018) and dynamic pulverization (Reches and Dewers, 2005). Extensive wall rock fragmentation without shear strain around amphibolite and eclogite facies faults provides some evidence for the high stresses caused by the propagation of seismic ruptures (Austrheim et al., 2017; Petley-Ragan et al., 2019). Recent experimental studies have reported the generation of amorphous material associated with fracturing and seismic slip under eclogite facies conditions (Incel et al., 2019). On the other hand, thermal radiation around frictional melt veins can drive recrystallization processes and form fine-grained dislocation-free aggregates (Bestmann et al., 2012, 2016). Signatures such as these are beneficial in recording the short-lived mechanical and thermal anomalies around seismic faults.

Here, we present a microstructural study of co-seismic microfractures in plagioclase from granulites in the Lindås Nappe of the Bergen Arcs in Western Norway at varying distances from a pseudotachylyte vein formed under lower crustal conditions (Fig. 1a). Our study builds directly on work done by Petley-Ragan et al. (2018), who analyzed the same microfractures in plagioclase with electron backscatter diffraction (EBSD). They concluded that the microfractures formed as a result of co-seismic damage in the wall rock adjacent to an earthquake fault and hypothesized that the grains recrystallized within the timescale of pseudotachylyte crystallization. We use a transmission electron microscope (TEM) equipped with an energy dispersive X-ray (EDX) detector to observe the fine-grained aggregates at the nanoscale. Our combined microstructural and chemical study aims at unravelling the thermomechanical evolution of plagioclase during and after earthquake rupture.

\section{Geological setting}

The Lindås Nappe of the Bergen Arcs of Western Norway is host to a population of seismic faults identified by the presence of millimetre- to centimetre-thick pseudotachylytes that cut through granulite facies anorthosite (Austrheim and Boundy, 1994). The pseudotachylytes contain either an eclogite-facies or amphibolite-facies mineralogy, and the wall rock damage adjacent to them is spatially related to finegrained products of the same metamorphic grade. The earthquakes took place within the lower crust during the Caledonian collision at 423-429 Ma (Jamtveit et al., 2019) and provoked fluid-driven amphibolitization at $600{ }^{\circ} \mathrm{C}$ and 0.8 $1.0 \mathrm{GPa}$ (Jamtveit et al., 2018), and eclogitization at 650 $750^{\circ} \mathrm{C}$ and 1.5-2.2 GPa (Jamtveit et al., 1990; Boundy et al., 1992; Glodny et al., 2008; Bhowany et al., 2017). The wall rock damage is best observed at the microscale due to the high spatial density of microfractures $(<50 \mu$ m thick) that criss-cross the wall rock mineral phases (Fig. 1). Microfractures in the most abundant mineral constituent of the granulite, plagioclase feldspar, were studied in detail by Petley-

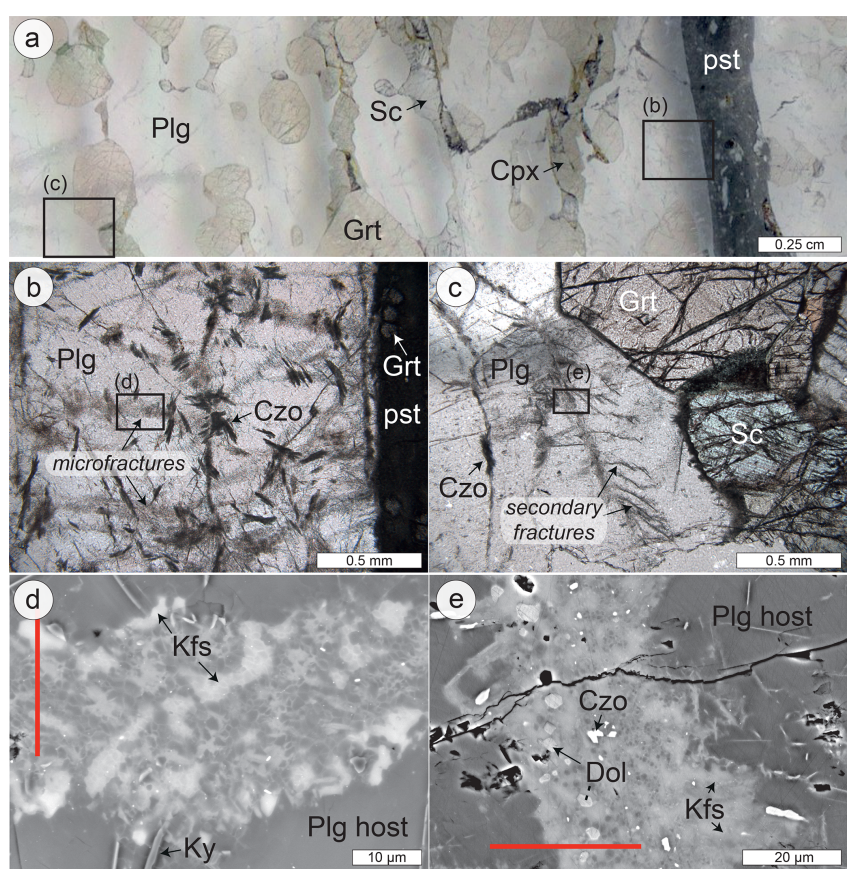

Figure 1. Fractured wall rock plagioclase. (a) Thin section scan of wall rock plagioclase (Plg), garnet (Grt), clinopyroxene (Cpx) and scapolite (Sc) adjacent to an eclogite facies pseudotachylyte (pst) on Holsnøy. (b) Fine-grained reaction products of clinozoisite (Czo) are associated with the microfractures; the box denotes the location of MF1. (c) Some microfractures in plagioclase display secondary cracking; the box denotes the location of MF2. (d) Backscatter electron image of MF1 with fine-grained plagioclase, alkali feldspar (Kfs) and minor kyanite (Ky). (e) Backscatter electron image of MF2 with fine-grained plagioclase, K-feldspar, dolomite (Dol) and clinozoisite. Red lines indicate the location of focused ion beam cuts for TEM analysis shown in Figs. 4-6.

Ragan et al. (2018) and are further investigated here at the nanoscale.

\section{Methods}

Photomicrographs of the plagioclase microstructures were taken with a Hitachi SU5000 field emission electron microscope (FE-SEM) at the Department of Geoscience at the University of Oslo. Chemical maps of the plagioclase were obtained with a Cameca SX100 electron microprobe analyzer (EMPA) at the University of Oslo's Department of Geoscience. The working conditions for the EMPA were a beam diameter of $1 \mu \mathrm{m}$, an accelerating voltage of $15 \mathrm{kV}$ and a beam current of $10 \mathrm{nA}$. The EMPA maps were used to perform mass balance calculations of three plagioclase microfractures. After segmenting the feldspar in the microfracture from their host, the average composition of the feldspar grains was compared to the average composition of the surrounding plagioclase host. All other phases were excluded in the mass balance calculation. 


\subsection{Electron backscatter diffraction}

Electron backscatter diffraction (EBSD) of the microfractures was done with a CamScan X500FE Crystal Probe equipped with an Nordlys detector (Oxford Instruments) at Géosciences Montpellier at the University of Montpellier in France. The EBSD detector was run with an accelerating voltage of $17 \mathrm{kV}$ and a step size of $0.2 \mu \mathrm{m}$ at a sample tilt of $70^{\circ}$ and a working distance of $25 \mathrm{~mm}$. The MTEX (version 4.4.0) MATLAB toolbox was used to obtain phase maps, pole figures and grain parameters from the EBSD data (Bachmann et al., 2010; Hielscher and Schaeben, 2008). In the phase maps, high-angle boundaries in black are defined by misorientations $\geq 10^{\circ}$, whereas low-angle boundaries in grey are defined by misorientations $<10^{\circ}$. Further details on the analysis of the EBSD data along with links to the raw data can be found in Petley-Ragan et al. (2018).

The grain sizes were extracted from the EBSD data to fit a probability density function (pdf) to their size distribution. The fitting method is the same as that presented in Aupart et al. (2018). The pdf returns the probability of encountering a grain of a given size using the Freedman-Diaconis rule to estimate the optimal number of bins for a given grain size population. The number of bins were restricted to 15-25. Grain size distributions have been fitted using two different power laws representative of small and large grains. The small grain size slope is referred to as $\alpha_{1}$, and the large grain size slope is referred to as $\alpha_{2}$.

\subsection{Transmission electron microscopy}

Focused ion beam (FIB) foils were prepared and TEM analyses were carried out at the Department of Earth Sciences at Utrecht University. The FEI Helios Nanolab G3 was used to cut FIB foils perpendicular to the length of the microfractures and $\sim 15-20 \mu \mathrm{m}$ in length in order to include both the host and microfracture constituents (Fig. 1d, e). The FEI Talos 200FX equipped with a highly sensitive 2D energy dispersive X-ray (EDX) system was used to obtain bright-field (BF), dark-field (DF) and high angular annual dark-field (HAADF) images in scanning TEM (STEM) mode. Large-area EDX maps were acquired of the entire FIB foil for MF1 and parts of the FIB foil for MF2.

\subsection{Thermal diffusion model}

In order to constrain the temperature history of each microfracture as a result of the nearby pseudotachylyte, we modelled the diffusion of heat from the pseudotachylyte into the wall rock. The diffusion of heat into the wall rock was calculated using a 1D steady-state thermal diffusion model from Bestmann et al. (2012). The model used an ambient eclogite facies temperature $\left(T_{\mathrm{b}}\right)$ of $700^{\circ} \mathrm{C}$ for the wall rock (Jamtveit et al., 1990) and a melting temperature $\left(T_{\mathrm{m}}\right)$ for granulite of $1500^{\circ} \mathrm{C}$ (Clerc et al., 2018). The model was cal- culated over a timescale $(t)$ of $1000 \mathrm{~s}$ from initial frictional heating along the fault. With these parameters, the temperature $(T)$ in Kelvin at a certain distance $(x)$ from the centre of the pseudotachylyte can be expressed as

$$
\begin{aligned}
T(x, t) & =1 / 2\left(T_{\mathrm{m}}-T_{\mathrm{b}}\right)\left\{\operatorname{erf}\left[(1-x / a) / 2(\kappa t)^{1 / 2}\right]\right. \\
& \left.+\operatorname{erf}\left[(1+x / a) / 2(\kappa t)^{1 / 2}\right]\right\} .
\end{aligned}
$$

At distances less than the half thickness of the pseudotachylyte $(a)$, a thermal diffusivity $(\kappa)$ of $0.72 \mathrm{~mm}^{2} / \mathrm{s}$ was used for the molten pseudotachylyte (Di Toro and Pennacchioni, 2004), whereas at distances greater than the half thickness, a thermal diffusivity $(\kappa)$ of $0.48 \mathrm{~mm}^{2} / \mathrm{s}$ was used to represent the granulite wall rock (Clerc et al., 2018). The temperature evolution at the distance representing each microfracture was studied.

\section{Results}

Two microfractures of dominantly plagioclase and Kfeldspar previously described by Petley-Ragan et al. (2018) were subject to further study with transmission electron microscopy (TEM). Both microfractures are located adjacent to a $1.3 \mathrm{~mm}$ thick eclogite facies pseudotachylyte. The microfracture orientations are independent of the crystallographic orientation of the host grains. The microfractures contain fine-grained aggregates (grain size $<5 \mu \mathrm{m}$ ) of dominantly plagioclase and K-feldspar (Fig. 2a, b). The microfracture from Fig. $1 \mathrm{~b}$ and $\mathrm{d}$ will hereafter be referred to as Microfracture 1 (MF1) and is located $1.25 \mathrm{~mm}$ away from pseudotachylyte. MF1 has a mean grain size of $1.73 \mu \mathrm{m}^{2}$ (Aupart et al., 2018). The microfracture from Figure 1c and e will be referred to as Microfracture 2 (MF2) and is located $1.8 \mathrm{~cm}$ away from the same pseudotachylyte (Fig. 1a). MF2 has a mean grain size of $2.14 \mu \mathrm{m}^{2}$ (Aupart et al., 2018). MF2 also contains a set of secondary fractures (Fig. 1c). The presence of secondary fractures indicates that MF2 experienced more shear deformation than MF1 (Petley-Ragan et al., 2018).

\subsection{Structure and composition of the microfractures}

The grains within the microfractures have a crystallographic preferred orientation (CPO) that is controlled by the host plagioclase on either side of the microfracture (Fig. 2c, d), and the K-feldspar grains have a CPO that mimics that of the plagioclase grains (Petley-Ragan et al., 2018). The grains also show a strong shape preferred orientation (SPO) with the long axis parallel to the pseudotachylyte wall irrespective of the microfracture orientation (Fig. 2e, f). Plagioclase compositions in the ranges $\mathrm{An}_{25-31}$ and $\mathrm{An}_{65-83}$ were measured in the microfractures. These originate from a host composition of $\mathrm{An}_{40}$ (Petley-Ragan et al., 2018). A similar bi- 


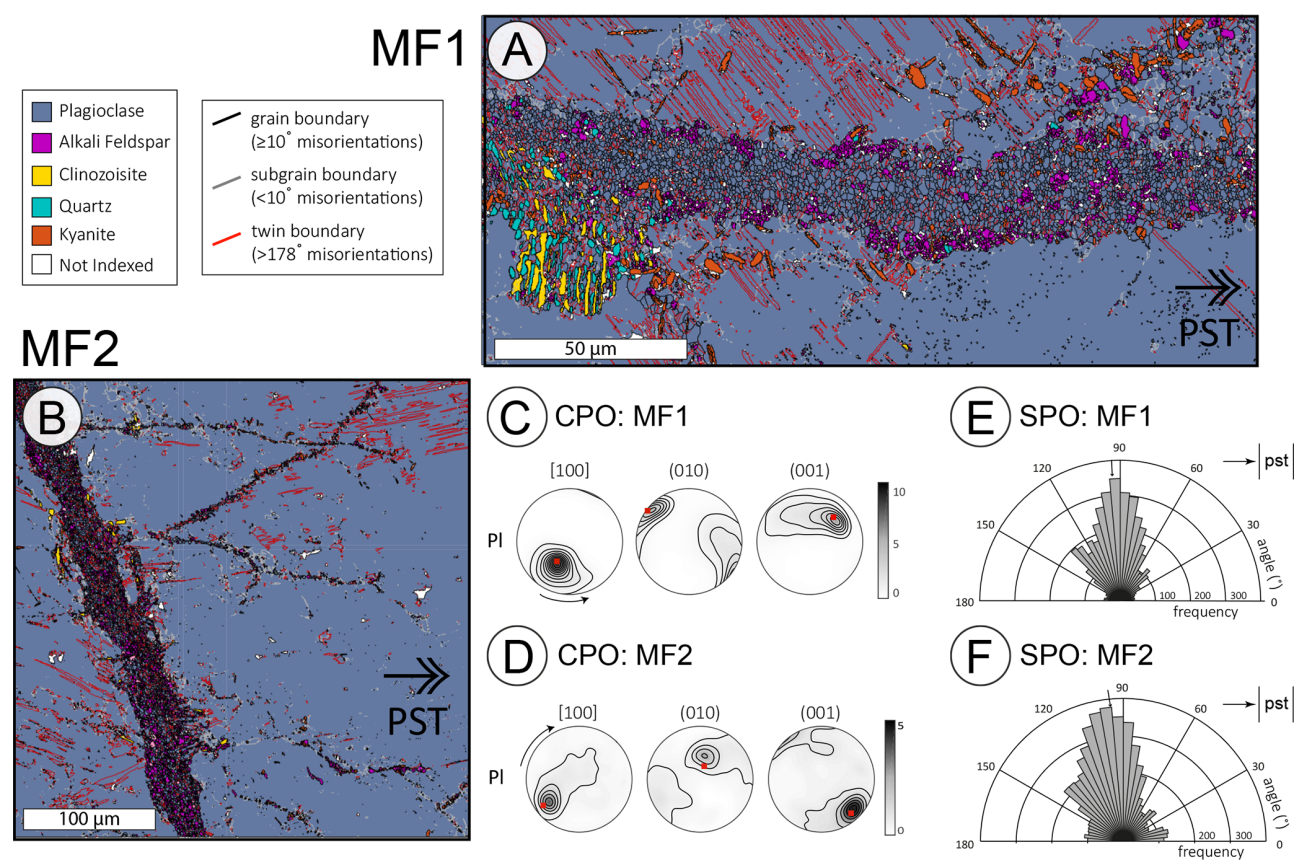

Figure 2. EBSD results of MF1 and MF2. Phase maps of (a) MF1 and (b) MF2. Pole figures of the plagioclase grains in (c) MF1 and (d) MF2. The red dot is the orientation of the host plagioclase. Rose diagrams of the long-axis distribution of the plagioclase grains in (e) MF1 and (f) MF2. The pseudotachylyte is to the right of all maps with vertical orientation. See Petley-Ragan et al. (2018) for more details on the EBSD methods and results.

modal range of plagioclase compositions were observed at garnet-plagioclase phase boundaries and in an amphibolite facies microshear zone at Isdal ca. $40 \mathrm{~km}$ northeast of Holsnøy (Mukai et al., 2014). Mass balance calculations based on three microfractures show that there is 5-11 times more $\mathrm{K}$ in the microfractures compared with the host composition (Fig. 3). Additionally, the microfractures are enriched in $\mathrm{Ca}$ and depleted in Na compared with their host. The microfractures locally consist of quartz and kyanite, or intergrown clinozoisite, quartz and K-feldspar. A few microfractures contain minor amounts of carbonates or phengite.

The distribution of plagioclase grain sizes from each microfracture are displayed in Fig. 4. Both distributions show power law slopes with a crossover from a shallow slope $(-1.1$ and -1.4 respectively) for small grain sizes to a steeper slope ( -2.7 and -3.4 respectively) for large grain sizes. The crossover occurs near the mean value of the grain size, and the steep slopes for the larger grains is reflected by the essentially equigranular appearance of this microstructure.

\subsection{TEM results}

A bright-field TEM (BF-TEM) image shows that MF1 contains dislocation-poor and dislocation-free grains of dominantly plagioclase and K-feldspar defined by straight grain boundaries with $120^{\circ}$ triple junctions (Fig. 5a). Few grains contain dislocations. In contrast, the host plagioclase con-

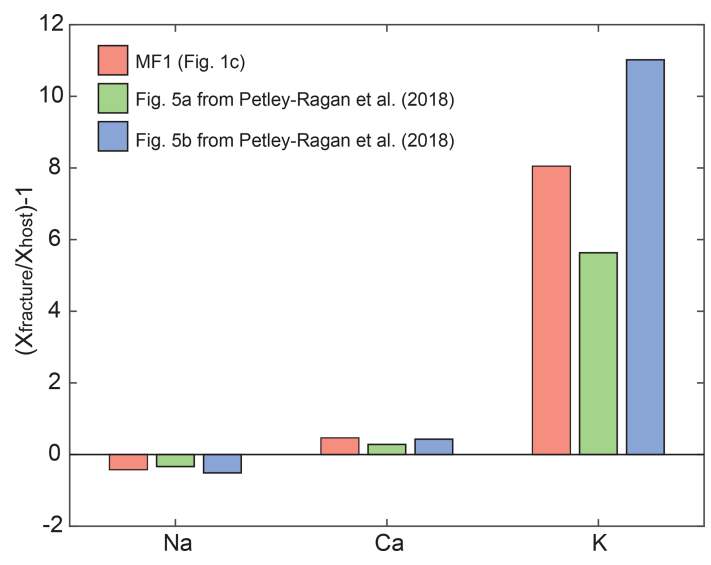

Figure 3. Mass balance of plagioclase microfractures. Three separate plagioclase microfractures were analyzed for $\mathrm{Na}, \mathrm{Ca}$ and $\mathrm{K}$. $X_{\text {fracture }}$ is the bulk composition of the fracture, and $X_{\text {host }}$ is the bulk composition of the adjacent plagioclase host.

tains a high density of dislocations that are locally arranged to form a subgrain wall. Ankerite $\left(\mathrm{Ca}(\mathrm{Fe}, \mathrm{Mg})\left(\mathrm{CO}_{3}\right)_{2}\right)$, grossular-rich garnet and sphene are additional phases in MF1, with apatite and rutile inclusions inside the grains, pinned along grain boundaries and concentrated along the subgrain wall in the host (Fig. 5b).

The EDX map of MF1 displays K-feldspar grains with homogeneous composition and plagioclase grains that are 


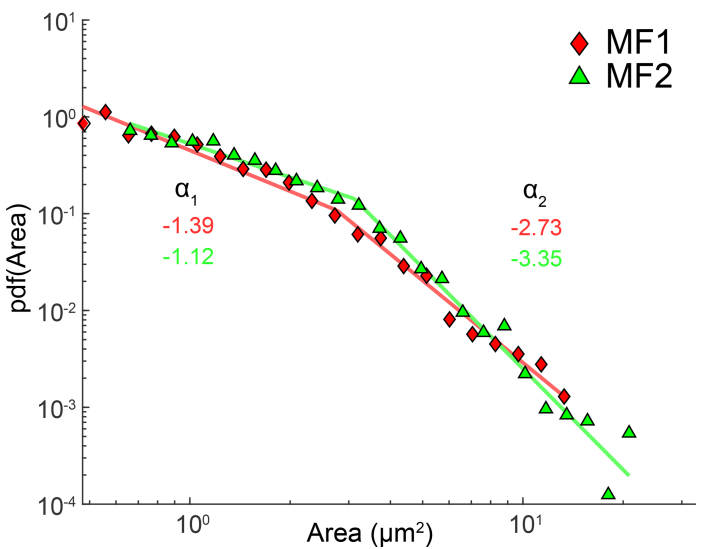

Figure 4. Grain size distribution of plagioclase grains in MF1 and MF2. A probability density function (pdf) was fitted to each distribution. The distributions display two different power law slopes (a) for the small and large grains. See Aupart et al. (2018) for details on the fitting method.

heterogeneous with respect to their $\mathrm{CaAl}$ and $\mathrm{NaSi}$ content (Fig. 5b). The K-feldspar grains are clustered together, creating a fabric dominated by grain boundaries instead of phase boundaries. The irregular composition distribution of $\mathrm{Na}$ and $\mathrm{Ca}$ in the plagioclase grains contradicts the backscatter electron image that suggests $\mathrm{Ca}$ zoning around the grains (Figs. 1d, 5b). Instead, the Ca-rich domains locally overlie areas with submicron lamellae (Fig. 6a-f). The lamellae are discontinuous throughout the plagioclase grains, and, locally, they are superimposed by tapered mechanical twins (Fig. 6a). Other grains contain both lamellae and twins that are spatially distinct but are parallel to each other (Fig. 6d). In some grains, the lamellae appear slightly curved (Fig. 6c), whereas the lamellae appear to form a "tweed" structure in other grains (Fig. 6f). The spacing between lamellae is approximately $10-30 \mathrm{~nm}$. The anorthite-rich domains have a composition $\left(\mathrm{An}_{65-83}\right.$; Petley-Ragan et al., 2018) within the Bøggild-Huttenlocher miscibility gap (Smith and Brown, 1988; McConnell, 2008). Similar intergrowths are not observed within the host plagioclase.

MF2 is similarly dominated by dislocation-poor grains of plagioclase and $\mathrm{K}$-feldspar with a number of grains displaying twinning (Fig. 7a). The twins of separate grains are approximately parallel to each other and to (010) of the host plagioclase (see Fig. 6 of Petley-Ragan et al., 2018), reinforcing the preservation of crystallographic orientations of the host through the fracturing and recovery process. Kyanite and a K-rich micaceous phase are additional phases in MF2. Apatite inclusions are present within the grains and pinned along grain boundaries. The fabric is characterized by $120^{\circ}$ triple junctions with rare dislocation-rich grains that display irregular boundaries (Fig. 7b).

The EDX map of MF2 shows clustered homogeneous Kfeldspar grains and zoned plagioclase grains (Fig. 7c), again creating a grain boundary-dominated fabric. Unlike MF1, the plagioclase grains in MF2 display Ca-enrichment at their grain boundaries and the submicron lamellae are absent. The Ca-rich rims are approximately $100-200 \mathrm{~nm}$ thick.

\subsection{Thermal model results}

The temperature evolutions of MF1 and MF2 over $1000 \mathrm{~s}$ after frictional heating along the pseudotachylyte are displayed in Fig. 8. According to our steady-state thermal diffusion model, the temperature evolutions of the microfractures are substantially different from one another. MF1 experienced a drastic increase in temperature by up to $\sim 135^{\circ} \mathrm{C}$ above ambient (reaching $\sim 835^{\circ} \mathrm{C}$ ) within a matter of seconds. By $100 \mathrm{~s}$ after heating, MF1 had cooled back to $740^{\circ} \mathrm{C}$ before gradual cooling to ambient temperature over the next few minutes. In contrast, MF2 located about $2 \mathrm{~cm}$ further away from the slip surface than MF1, experienced a gradual increase to a peak temperature of $\sim 15^{\circ} \mathrm{C}$ above ambient after $300 \mathrm{~s}$. By $1000 \mathrm{~s}$ after frictional slip along the fault, both microfractures had reached similar temperatures near ambient.

\section{Discussion}

The micro- and nanoscale structures of the microfractures described above characterize the evolution of wall rock plagioclase resulting from the stress and temperature perturbations created near a lower crustal earthquake slip plane. The dislocation-free nature of almost all grains in MF1 and MF2 suggest nearly complete annealing of the material within the microfractures (Figs. 5a, 7a). The grain fabric is dominated by straight phase and grain boundaries, $120^{\circ}$ triple junctions and pinned inclusions suggesting extensive grain boundary migration. The inheritance of the crystallographic orientation of the host plagioclase and its twins within the grains points towards an initial annealing process that is able to transfer and preserve crystallographic information. A pronounced shape preferred orientation (SPO) of the grains parallel to the pseudotachylyte wall (Fig. 2) suggests that annealing was initiated while a stress or thermal field with a consistent orientation relative to the seismic slip plane was still present (Petley-Ragan et al., 2018). If these fields were generated by an earthquake, it would constrain the timescale of initial microfracture annealing to the duration of pseudotachylyte crystallization and cooling (seconds to minutes).

The observation of lamellae structures in MF1 but not MF2 suggests that unmixing of plagioclase grains of intermediate compositions occurred within the timescale of the local thermal anomaly. The Bøggild-Huttenlocher miscibility gap takes place below $800^{\circ} \mathrm{C}$ (Carpenter, 1994; McConnell, 2008), approximately $20 \mathrm{~s}$ after heating in MF1 (Fig. 8). However, chemical diffusion in silicates is known to be extremely slow under dry conditions (Pennacchioni et al., 2020; Dunkel et al., 2021) and would require the presence of flu- 


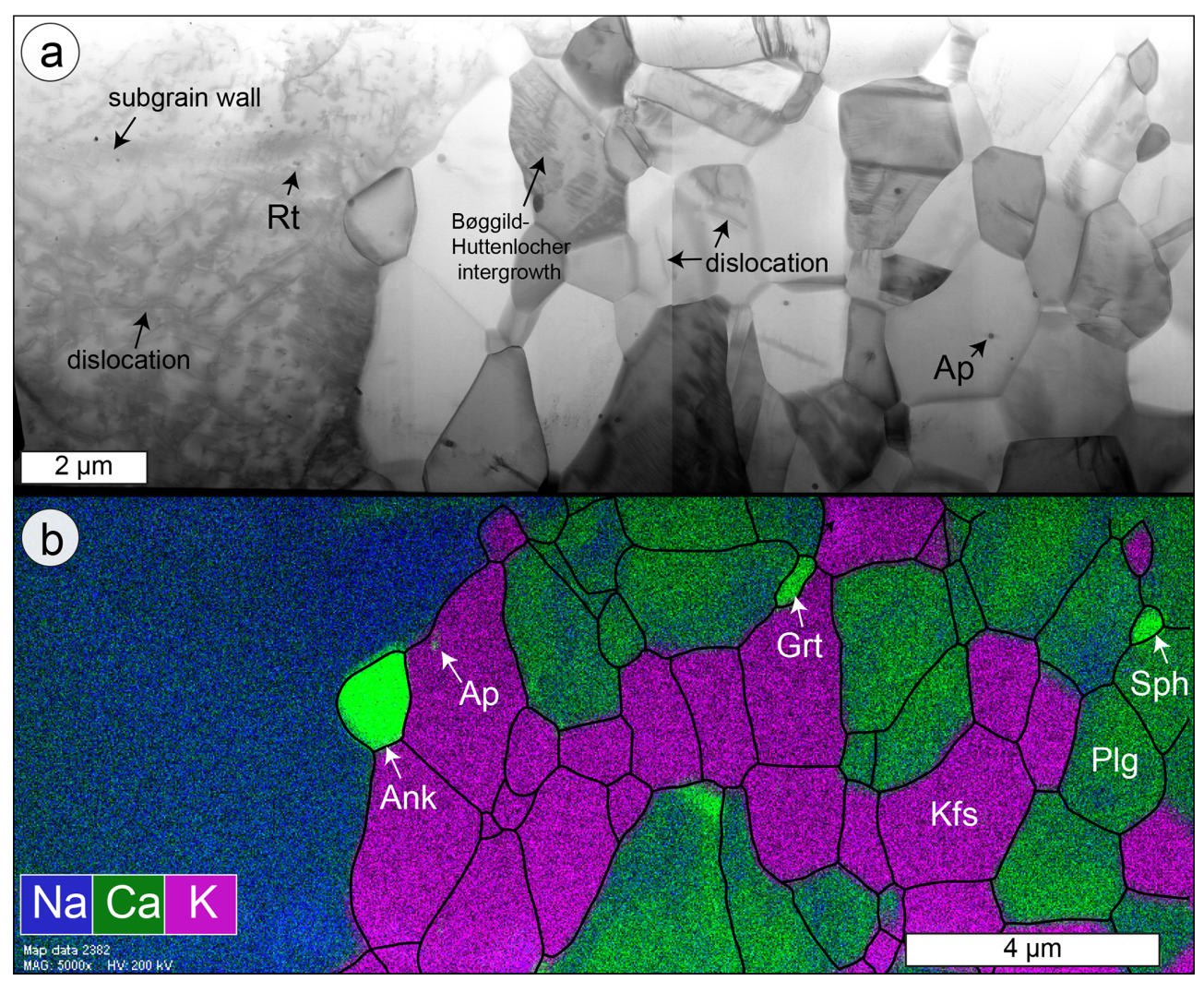

Figure 5. Microstructures of MF1. (a) BF-STEM image of the entire FIB cut from Fig. 1d. The plagioclase (Plg) host to the left is rich in dislocations, whereas the grains within the microfracture to the right are poor to absent with respect to dislocations. Apatite (Ap) and rutile (Rt) inclusions are present within the host and the grains, as well as pinned along grain boundaries in the microfracture. (b) EDX map overlain with grain and phase boundaries (black). Ankerite (Ank), garnet (Grt) and sphene (Sph) are additional phases within the microfracture.

ids. Fluid introduction is also reflected by the presence of hydrous phases, such as clinozoisite and phengite, and carbonates within these microfractures, as well as a significant increase in $\mathrm{K}$ compared with the host wall rock plagioclase (Fig. 3). Furthermore, our mass balance illustrates an increase in $\mathrm{Ca}$ in the plagioclase aggregates compared with their host which creates a composition that promotes unmixing below $800^{\circ} \mathrm{C}$. Thus, our observations provide unequivocal evidence that dynamic rupturing and subsequent seismic slip were followed by fluid infiltration within seconds, altering the microfracture composition prior to recovery.

If grain recovery and development of the pronounced SPO had occurred over much longer timescales, MF1 and MF2 would have reached similar temperature conditions (Fig. 8) and the SPO would have been controlled by a far-field stress. Assuming that the long axes of the plagioclase grains are oriented perpendicular to the largest stress axis $\left(\sigma_{1}\right)$, the observed SPO would imply that the far field $\sigma_{1}$ was perpendicular to the slip surface. This is inconsistent with the fault being developed as a shear fracture driven by the same farfield stress that would have controlled the SPO. Therefore, we propose that the observed SPO is more readily explained by a fast recovery process and a local stress field that is con- trolled by the geometry of the pseudotachylyte. This is consistent with studies by Bestmann et al. (2012, 2016), who suggest that dynamic recrystallization of damaged quartz occurred within the short-lived thermal anomaly related to a seismic event.

The power law grain size distributions of the MF1 and MF2 grain populations (Fig. 4) also support relatively rapid recovery as a slow steady-state growth process is expected to lead to a log-normal distribution of grain sizes (Aupart et al., 2018). The extremely steep slopes characterizing the larger grain size fraction of the plagioclase aggregates in the MF1 and MF2 microfractures are similar to what has previously been described from pulverized garnet and olivine from the wall rocks of lower crustal seismic faults (Aupart et al., 2018). The origin of this scaling is, however, not fully understood.

\subsection{Pre-recovery state of plagioclase}

Deformation experiments performed under eclogite facies conditions may offer some insight into the state of the microstructures within the microfractures prior to recovery. Incel et al. (2017, 2019) observed brittle fractures filled 


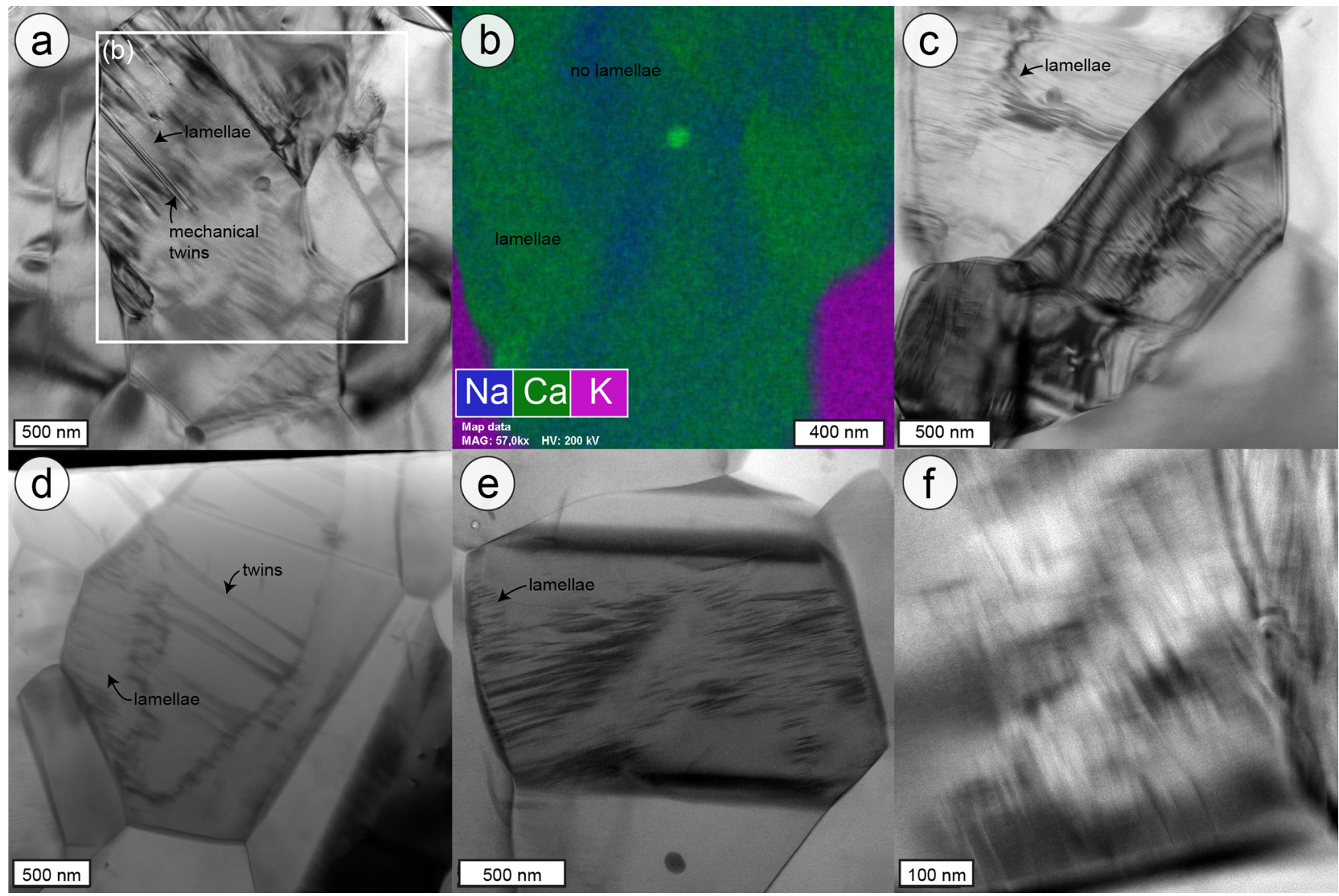

Figure 6. Plagioclase intergrowths in MF1. (a) BF-TEM image of the submicron lamellae in a plagioclase grains that are overlain by mechanical twins. (b) EDX map showing the distribution of $\mathrm{Ca}$ and $\mathrm{Na}$ in the plagioclase grains associated with the intergrowth in panel (a). The Ca-rich domains overlay the lamellae. (c) BF-TEM image of lamellae in two separate grains that show slight curvature. (d) BF-STEM image of discontinuous lamellae within a grain that hosts twins in its core. (e) STEM bright-field image of discontinuous lamellae within a plagioclase grain. (f) Bright-field TEM image of lamellae resembling "tweed" exsolution within plagioclase.

with amorphous material during deformation experiments on blueschist under eclogite facies conditions. They interpreted the amorphous material to result from shock loading during the propagation of a dynamic rupture. Although their experiments involved a short recovery time $(<1 \mathrm{~h})$, some of the amorphous material recrystallized, creating idiomorphic garnet crystals with a size of $\sim 20 \mathrm{~nm}$.

Amorphization of plagioclase feldspar is dependent on pressure $(P)$, temperature $(T)$, composition $(X)$, compression rate $(P / t)$ and pressure duration $(t)$. Amorphization that is strongly dependent on temperature is commonly referred to as heterogeneous amorphization or melting, and it is a relatively slow process due to its dependence on the diffusion of atoms (Wolf et al., 1990). On the other hand, amorphization that is strongly dependent on pressure, pressureinduced amorphization, may be static or dynamic depending on the compression rate (Sharma and Sikka, 1996). In the following, we will discuss pressure-induced amorphization. For anorthite-rich compositions $\left(\mathrm{An}_{51-100}\right)$ complete pressure- induced amorphization occurs at pressures $\geq 13 \mathrm{GPa}$ and $T=660^{\circ} \mathrm{C}$, whereas albite-rich $\left(\mathrm{An}_{2}\right)$ compositions are not completely amorphous until $P \geq 26 \mathrm{GPa}$ and $T=950^{\circ} \mathrm{C}$ (Daniel et al., 1997; Kubo et al., 2009; Tomioka et al., 2010). A short pressure duration results in lower degrees of amorphization (Tomioka et al., 2010), whereas high compression rates of $10^{1}-10^{2} \mathrm{GPa} / \mathrm{s}$ can reduce the pressure required for amorphization (Sims et al., 2019). The short-lived (microseconds) high-intensity $\left(10^{6} \mathrm{GPa} / \mathrm{s}\right)$ conditions in the proximity of earthquake rupture tips (Reches and Dewers, 2005) may partially amorphize plagioclase feldspar $\left(\mathrm{An}_{40}\right)$ in the wall rock, even if the local pressure for complete amorphization is not reached. The presence of asymmetric tensile cracks on some of the microfractures indicates that the propagation velocity of the microfractures approached the shear wave velocity (Petley-Ragan et al., 2018), inducing similar shortlived high-intensity stresses within their vicinity. Therefore, a mixture of amorphous material with remnant fragments may 


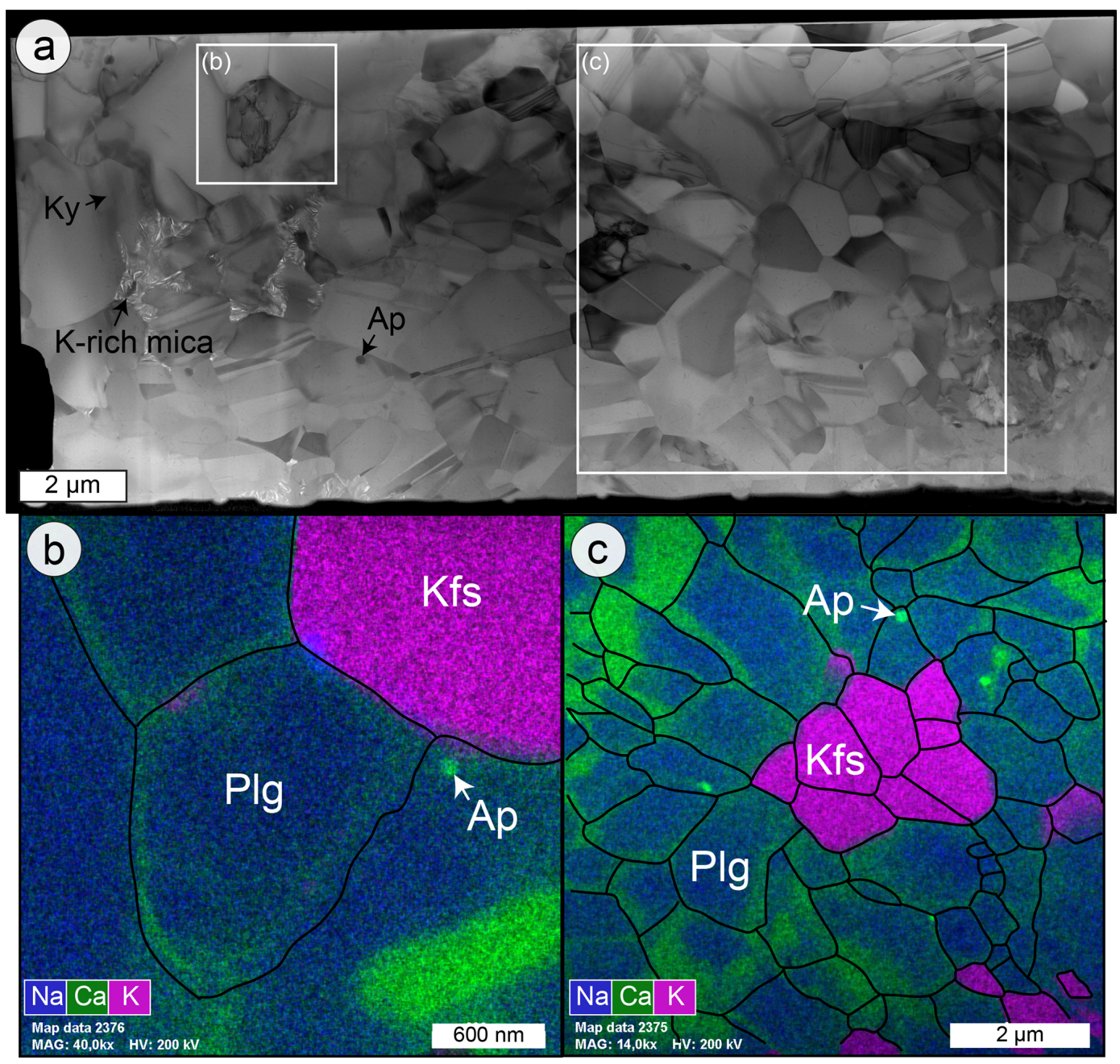

Figure 7. Microstructures of MF2. (a) Bright-field image of the entire FIB cut from Fig. 1e. The plagioclase (Plg) microfracture contains dislocation-free grains with some twins. (b) EDX map of a dislocation-rich grain overlain with grain and phase boundaries (black). (c) EDX map of the area in panel (a) overlain with grain and phase boundaries (black). The Ca-rich domains are present along grain boundaries.

have been present within the microfractures immediately after earthquake and microfracture rupture.

Repolymerization of amorphous material on the microfracture walls and remnant fragments would directly transfer the crystallographic orientation of the host. Crystallographic information may also be preserved by the presence of short-range atomic order within amorphous material, allowing for immediate repolymerization without the aid of a fragment nucleus (Casey et al., 1993; Konrad-Schmolke et al., 2018). Repolymerization has also been suggested to occur directly along crystal lattice defects where amorphous material originates (Konrad-Schmolke et al., 2018). In this context, dislocations within the grains may have healed much more quickly than would be expected from dislocation migration recrystallization, and the fragments would have experienced healing from multiple available interfaces. Other preferred areas of repolymerization were likely parallel to the minimum principal stress direction, growing grains with a stress-dependent SPO. Therefore, recrystallization from an amorphous material may be a likely candidate to create the observed dislocation-free fabric with a strong SPO within seconds to minutes after seismic slip.

\subsection{The role of fluids}

Recent studies of seismic faults in lower crustal granulites have demonstrated that both mass transfer and microstructural recovery is very limited under dry conditions. Even relict amorphous material has been reported from within the pseudotachylyte itself (Pennacchioni et al., 2020; Dunkel et al., 2021). The microstructures and mineralogical effects observed in the wall rock microfractures in our study, including the presence of minor hydrous phases and carbonates, clearly reflect the introduction of fluids at a very early stage after earthquake development. The maximum rate of fluid migration in the wake of a dynamic rupture connected to a fluid 


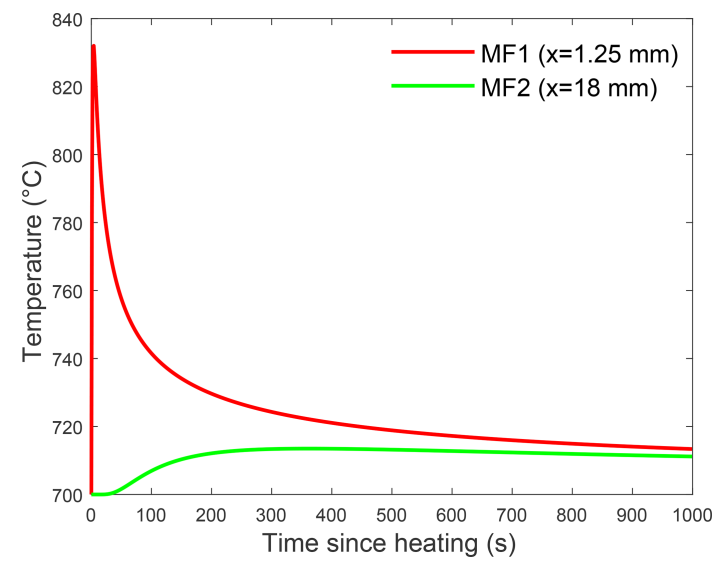

Figure 8. Results of the steady-state thermal diffusion model. The temperature at each microfracture is calculated relative to an ambient eclogite facies temperature of $700{ }^{\circ} \mathrm{C}$ over a timescale of $1000 \mathrm{~s}$ after heating up to $1500^{\circ} \mathrm{C}$ along the fault surface. The heat is considered to first travel through the molten pseudotachylyte $\left(k=0.72 \mathrm{~mm}^{2} / \mathrm{s}\right)$ before diffusing through the wall rock $(k=$ $\left.0.48 \mathrm{~mm}^{2} / \mathrm{s}\right)$. Close to the pseudotachylyte, MF1 experienced a drastic temperature increase and steep cooling, whereas MF2 experienced only a slight temperature increase. See Sects. 4 and 5 for details.

reservoir is still poorly constrained. However, unpublished modelling results by our group at the University of Oslo indicate that incipient water migration rates in tensile microcracks may reach a significant fraction of the Rayleigh velocity.

The consumption of fluids by fluid-consuming reactions in the wall rocks would maintain fluid pressure gradients that would drive sustained fluid migration into the wall rocks as demonstrated by Malvoisin et al. (2020). These authors presented petrological data and numerical models indicating that densification associated with eclogite-forming reactions would occur within weeks in the presence of fluids and would consume fluids injected during and immediately after an earthquake.

The source of fluids during eclogitization in the Bergen Arcs has been discussed for several decades. Svensen et al. (1999) demonstrated that aqueous brines entering a dry granulite under eclogite facies conditions may become extremely enriched in a variety of solutes during hydration reactions and, thus, represent an effective medium for substantial mass transfer in a relatively fluid-poor system. This may explain the chemical difference between the original wall rock plagioclase and the feldspar aggregates observed in the microfractures (Fig. 3). Recently, Jamtveit et al. (2021) showed that shear heating of Lower Paleozoic metapelites located in the immediate footwall of the Lindås Nappe may have dehydrated and contributed to fluid production during Nappe emplacement. The extent to which this fluid production has contributed to the brittle failure of the overlying lower crust is still not well constrained.

\section{Conclusions}

Our nanostructural observations are relevant for understanding plagioclase deformation during and after an earthquake in the lower crust, prior to any subsequent shear zone development. We propose that plagioclase within the microfractures experienced partial amorphization at peak pressures coeval with earthquake propagation and microfracturing in the wall rock. Repolymerization on microfracture walls and remnant fragments formed a strong CPO in the grains, while shortrange atomic ordering in the direction parallel to the minimum principal stress formed a distinct SPO that is parallel to the nearby pseudotachylyte. Repolymerization and recovery within the time frame of pseudotachylyte formation explains the presence of dislocation-free grains, as has been interpreted for similar structures observed in quartz (Bestmann et al., 2012, 2016). In close proximity to the pseudotachylyte, wall rock temperatures reached $\sim 850^{\circ} \mathrm{C}$ before rapidly cooling back to ambient eclogite facies conditions and into the plagioclase miscibility gap. This caused exsolution of intermediate plagioclase compositions and the formation of nanoscale lamellae. Yet, the complete recrystallization of the material in the microfractures and the exsolution of plagioclase to form lamellae would not have been possible without the presence of fluids. We hypothesize that the lamellae described here are a unique signature of fluid-driven recrystallization within plagioclase-rich wall rock in the vicinity of pseudotachylyte. The observed microstructures and associated mass transfer demonstrate that externally derived fluids entered the wall rock microfractures at the timescale of the earthquake.

Data availability. Raw electron backscatter diffraction and geochemical data are available on the Open Science Framework: https: //osf.io/g36m7/ (Petley-Ragan, 2021).

Sample availability. Rock samples are available from Arianne J. Petley-Ragan, and FIB foils are available from Oliver Plümper.

Author contributions. BJ designed the project. AJPR collected the samples, and obtained and analyzed the EBSD and geochemical data. BI helped collect and interpret the EBSD data. OP cut the FIB foils, and obtained and interpreted the TEM images. AJPR, OP and $\mathrm{BJ}$ were part of discussions. AJPR and BJ wrote the paper.

Competing interests. The authors declare that they have no conflict of interest.

Acknowledgements. We thank Håkon Austrheim for field guidance on Holsnøy and hospitality in Western Norway. We are grate- 
ful to Xin Zhong for help with the mass balance calculations, to Fabrice Barou for assistance with EBSD measurements and to Muriel Erambert for help on the electron microprobe. Lastly, we greatly appreciate the thorough reviews by Mark Pearce and an anonymous reviewer that improved the paper.

Financial support. This research has been supported by the European Research Council (grant nos. 669972, DIME, and 852069, nanoEARTH) and the Natural Sciences and Engineering Research Council of Canada (grant no. 489392).

Review statement. This paper was edited by David Healy and reviewed by Mark Pearce and one anonymous referee.

\section{References}

Aupart, C., Dunkel, K. G., Angheluta, L., Austrheim, H., Ildefonse, B., MaltheSørenssen, A., and Jamtveit, B.: Olivine grain size distributions in faults and shear zones: Evidence for nonsteady state deformation, J. Geophys. Res.-Sol. Ea., 123, 7421-7443, https://doi.org/10.1029/2018JB015836, 2018.

Austrheim, H. and Boundy, T. M.: Pseudotachylytes generated during seismic faulting and eclogitization of the deep crust, in: Science, 82-83, http://www.jstor.org/stable/2884364 (last access: 9 April 2021), https://doi.org/10.1126/science.265.5168.82, 1994.

Austrheim, H., Dunkel, K. G., Plümper, O., Ildefonse, B., Liu, Y., and Jamtveit, B.: Fragmentation of wall rock garnets during deep crustal earthquakes, Sci. Adv., 3, e1602067, https://doi.org/10.1126/sciadv.1602067, 2017.

Bachmann, F., Hielscher, R., and Schaeben, H.: Texture analysis with MTEX - free and open source software toolbox, Solid State Phenom., 160, 63-68, https://doi.org/10.4028/www.scientific.net/SSP.160.63, 2010.

Bestmann, M., Pennacchioni, G., Nielsen, S., Göken, M., and de Wall, H.: Deformation and ultrafine dynamic recrystallization of quartz in pseudotachylyte-bearing brittle faults: A matter of a few seconds, J. Struct. Geol., 38, 21-38, https://doi.org/10.1016/j.jsg.2011.10.001, 2012.

Bestmann, M., Panncchioni, G., Mostefaoui, S., Göken, M., and de Wall, H.: Instantaneous healing of microfractures during coseismic slip: Evidence from microstructure and $\mathrm{Ti}$ in quartz geochemistry within an exhumed pseudotachylyte-bearing fault in tonalite, Lithos, 254-255, 84-93, https://doi.org/10.1016/j.lithos.2016.03.011, 2016.

Bhowany, K., Hand, M., Clark, C., Kelsey, D. E., Reddy, S. M., Pearce, M. A., Tucker, N. M., and Morrissey, L. J.: Phase equilibria modelling constraints on P-T conditions during fluid catalysed conversion of granulite to eclogite in the Bergen Arcs, Norway, J. Metamorph. Geol., 36, 315-342, https://doi.org/10.1111/jmg.12294, 2017.

Boundy, T. M., Fountain, D. M., and Austrheim, H.: Structural development and petrofabrics of eclogite facies shear zones, Bergen Arcs, western Norway: implications for deep crustal deformational processes, J. Metamorph. Geol., 10, 127-146, https://doi.org/10.1111/j.1525-1314.1992.tb00075.x, 1992.
Carpenter, M. A.: Mechanisms and kinetics of Al-Si ordering in anorthite: I. Incommensurate structure and domain coarsening, Am. Mineral., 76, 1110-1119, 1991.

Casey, W. H., Westrich, H. R., Banfield, J. F., Ferruzi, G., and Arnold, G. W.: Leaching and reconstruction at the surfaces of dissolving chain-silicate minerals, Nature, 366, 253-256, https://doi.org/10.1038/366253a0, 1993.

Clerc, A., Renard, F., Austrheim, H., and Jamtveit, B.: Spatial and size distributions of garnets grown in a pseudotachylyte generated during a lower crustal earthquake, Tectonophysics, 733, 159-170, https://doi.org/10.1016/j.tecto.2018.02.014, 2018.

Daniel, I., Gillet, P., McMillan, P. F., Wolf, G., and Verhelst, M. A.: High-pressure behavior of anorthite: Compression and amorphization, J. Geophys. Res.-Sol. Ea., 102, 10313-10325, https://doi.org/10.1029/97JB00398, 1997.

Di Toro, G. and Pennacchioni, G.: Superheated friction-induced melts in zoned pseudotachylytes within the Adamello tonalites (Italian Southern Alps), J. Struct. Geol., 26, 1783-1801, https://doi.org/10.1016/j.jsg.2004.03.001, 2004.

Dunkel, K. G., Morales, L. F. G., and Jamtveit, B.: Pristine microstructures in pseudotachylytes formed in dry lower crust, Lofoten, Norway, Philos. T. Roy. Soc. A, 379, 20190423, https://doi.org/10.1098/rsta.2019.0423, 2021.

Glodny, J., Kühn, A., and Austrheim, H.: Geochronology of fluidinduced eclogite and amphibolite facies metamorphic reactions in subduction-collision system, Bergen Arcs, Norway, Contrib. Mineral. Petr., 156, 27-48, https://doi.org/10.1007/s00410-0070272-y, 2008.

Hielscher, R. and Schaeben, H.: A novel pole figure inversion method: specification of the MTEX algorithm, J. Appl. Crystallogr., 41, 1024-1037, https://doi.org/10.1107/S0021889808030112, 2008.

Incel, S., Hilairet, N., Labrousse, L., John, T., Deldicque, D., Farrand, T., Wang, Y., Renner, J., Morales, L., and Schubnel, A.: Laboratory earthquakes triggered during eclogitization of lawsonite-bearing blueschist, Earth Planet. Sc. Lett., 459, 320331, https://doi.org/10.1130/G45527.1, 2017.

Incel, S., Schubnel, A., John, T., Freeman, H., Wang, Y., Renard, F., and Jamtveit, B.: Experimental evidence for wall rock pulverization during dynamic rupture at ultra-high pressure conditions, Earth Planet. Sc. Lett., 528, 115832, https://doi.org/10.1016/j.epsl.2019.115832, 2019.

Jamtveit, B., Bucher-Nurminen, K., and Austrheim, H.: Fluid controlled eclogitization of granulites in deep crustal shear zones, Bergen Arcs, Western Norway, Contrib. Mineral. Petr., 104, 184193, https://doi.org/10.1007/BF00306442, 1990.

Jamtveit, B., Austrheim, H., and Putnis, A.: Disequilibrium metamorphism of stressed lithosphere, Earth-Sci. Rev., 154, 1-13, https://doi.org/10.1016/j.earscirev.2015.12.002, 2016.

Jamtveit, B., Moulas, E., Andersen, T. B., Austrheim, H., Corfu, F., Petley-Ragan, A., and Schmalholz, S. M.: High pressure metamorphism caused by fluid induced weakening of deep continental crust, Sci. Rep.-UK, 8, 17011, https://doi.org/10.1038/s41598-018-35200-1, 2018.

Jamtveit, B., Petley-Ragan, A., Incel, S., Dunkel, K. G., Aupart, C., Austrheim, H., Corfu, F., Menegon, L., and Renard, F.: The effects of earthquakes and fluids on the metamorphism of the lower continental crust, J. Geophys. Res.-Sol. Ea., 124, 77257755, https://doi.org/10.1029/2018JB016461, 2019. 
Jamtveit, B., Dunkel, K., Petley-Ragan, A., Austrheim, H., Corfu, F., and Schmid, D. W.: Rapid fluid-driven transformation of lower continental crust associated with thrust-induced shear heating, Lithos, in press, 2021.

Konrad-Schmolke, M., Halama, R., Wirth, R., Thomen, A., Klitscher, N., Morales, L., Schreiber, A., and Wilke, F. D. H.: Mineral dissolution and reprecipitation mediated by an amorphous phase, Nat. Commun., 9, 1637, https://doi.org/10.1038/s41467018-03944-z, 2018.

Kubo, T., Kimura, M., Kato, T., Nishi, M., Tominaga, A., Kikegawa, T., and Funakoshi, K.: Plagioclase breakdown as an indicator for shock conditions of meteorites, Nat. Geosci., 3, 41-45, https://doi.org/10.1038/ngeo704, 2009.

Malvoisin, B., Austrheim, H., Hetényi, G., Reynes, J., Hermann, J., Baumgartner, L. P., and Podladchikov, Y. Y.: Sustainable densification of the deep crust, Geology, 48, 673-677, https://doi.org/10.1130/G47201.1, 2020.

Marti, S., Stünitz, H., Heilbronner, R., Plümper, O., and Drury, M.: Experimental investigation of the brittle-viscous transition in mafic rocks - Interplay between fracturing, reaction, and viscous deformation, J. Struct. Geol., 105, 62-79, https://doi.org/10.1016/j.jsg.2017.10.011, 2017.

McConnell, J.: The origin and characteristics of incommensurate structures in the plagioclase feldspars, Can. Mineral., 46, 13891400, https://doi.org/10.3749/canmin.46.6.1389, 2008.

Menegon, L., Stünitz, H., Nasipuri, P., Heilbronner, R., and Svahnberg, H.: Transition from fracturing to viscous flow in granulite facies perthitic feldspar (Lofoten, Norway), J. Struct. Geol., 48, 95-112, https://doi.org/10.1016/j.jsg.2012.12.004, 2013.

Mukai, H., Austrheim, H., Putnis, C. V., and Putnis, A.: Textural evolution of plagioclase feldspar across a shear zone: Implications for deformation mechanism and rock strength, J. Petrol., 55, 1457-1477, https://doi.org/10.1093/petrology/egu030, 2014.

Okudaira, T., Shigematsu, N., Harigane, Y., and Yoshida, K.: Grain size reduction due to fracturing and subsequent grainsize-sensitive creep in lower crustal shear zone in the presence of a $\mathrm{CO}_{2}$-bearing fluid, J. Struct. Geol., 95, 171-187, https://doi.org/10.1016/j.jsg.2016.11.001, 2016.

Papa, S., Pennacchioni, G., Angel, R. J., and Faccenda, M.: The fate of garnet during (deep-seated) coseismic frictional heating: The role of thermal shock, Geology, 46, 471-474, https://doi.org/10.1130/G40077.1, 2018.

Pennacchioni, G., Scambelluri, M., Bestmann, M., Notini, L., Nimis, P., Plümper, O., Faccenda, M., and Nestola, F.: Record of intermediate-depth subduction seismicity in a dry slab from an exhumed ophiolite, Earth Planet. Sc. Lett., 548, 116490, https://doi.org/10.1016/j.epsl.2020.116490, 2020.
Petley-Ragan, A.: Nano-scale earthquake records preserved in plagioclase microfractures from the lower continental crust, Dataset, https://doi.org/10.17605/OSF.IO/G36M7, last access: 4 February 2021.

Petley-Ragan, A., Dunkel, K. G., Austrheim, H., Ildefonse, B., and Jamtveit, B.: Microstructural records of earthquakes in the lower crust and associated fluid-driven metamorphism in plagioclaserich granulites, J. Geophys. Res.-Sol. Ea., 123, 3729-3746, https://doi.org/10.1029/2017JB015348, 2018.

Petley-Ragan, A., Ben-Zion, Y., Austrheim, H., Ildefonse, B., Renard, F., and Jamtveit, B.: Dynamic earthquake rupture in the lower crust, Sci. Adv., 5, 7, https://doi.org/10.1126/sciadv.aaw0913, 2019.

Reches, Z. and Dewers, T. A.: Gouge formation by dynamic pulverization during earthquake rupture, Earth Planet. Sc. Lett., 235, 361-374, https://doi.org/10.1016/j.epsl.2005.04.009, 2005.

Sharma, S. and Sikka, S.: Pressure Induced Amorphization of Materials, Prog. Mater. Sci., 40, 1-77, 1996.

Sims, M., Jaret, S. J., Carl, E.-R., Rhymer, B., Schrodt, N., Mohrholz, V., Smith, J., Konopkova, Z., Liermann, H.-P., Glotch, T. D., and Ehm, L.: Pressure-induced amorphization in plagioclase feldspars: A time-resolved powder diffraction study during rapid compression, Earth Planet. Sc. Lett., 507, 166-174, https://doi.org/10.1016/j.epsl.2018.11.038, 2019.

Smith, J. V. and Brown, W. L.: Feldspar Minerals, Springer, Berlin, Germany, vol. 1, 1988.

Soda, Y. and Okudaira, T.: Microstructural evidence for the deep pulverization in a lower crustal meta-anorthosite, Terra Nova, 30, 399-405, https://doi.org/10.1111/ter.12355, 2018.

Svahnberg, H. and Piazolo, S.: The initiation of strain localisation in plagioclase-rich rocks: Insights from detailed microstructural analyses, J. Struct. Geol., 32, 1404-1416, https://doi.org/10.1016/j.jsg.2010.06.011, 2010.

Svensen, H., Jamtveit, B., Yardley, B. W. D., Engvik, A. K., Austrheim, H., and Broman, C.: Lead and bromine enrichment in eclogite facies fluids: Extreme fractionation during lower-crustal hydration, Geology, 27, 467-470, https://doi.org/10.1130/00917613(1999)027<0467:LABEIE>2.3.CO;2, 1999.

Tomioka, N., Kondo, H., Kunikata, A., and Nagai, T.: Pressureinduced amorphization of albitic plagioclase in an externally heated diamond anvil cell, Geophys. Res. Lett., 37, L21301, https://doi.org/10.1029/2010GL044221, 2010.

Wolf, D., Okamoto, P., Yip, S., Lutsko, J. F., and Kluge, M.: Thermodynamic parallels between solid-state amorphization and melting, J. Mater. Res., 5, 286-301, https://doi.org/10.1557/JMR.1990.0286, 1990. 